Article

\title{
Novel Mitochondrial DNA Lineage Found among Ochlerotatus communis (De Geer, 1776) of the Nordic-Baltic Region
}

\author{
Heli Kirik ${ }^{1, *(\mathbb{C})}$, Lea Tummeleht ${ }^{2}\left(\mathbb{D}\right.$, Tobias Lilja ${ }^{3}$ and Olavi Kurina ${ }^{1}$ \\ 1 Institute of Agricultural and Environmental Sciences, Estonian University of Life Sciences, \\ Friedrich Reinhold Kreutzwaldi 5D, 51006 Tartu, Estonia; olavi.kurina@emu.ee \\ 2 Institute of Veterinary Medicine and Animal Sciences, Estonian University of Life Sciences, \\ Friedrich Reinhold Kreutzwaldi 62, 51006 Tartu, Estonia; lea.tummeleht@gmail.com \\ 3 Department of Microbiology, Swedish National Veterinary Institute, 75189 Uppsala, Sweden; \\ tobias.lilja@sva.se \\ * Correspondence: heli.kirik@emu.ee; Tel.: +372-564-96490
}

Received: 14 May 2020; Accepted: 23 June 2020; Published: 26 June 2020

check for updates

\begin{abstract}
The Ochlerotatus (Oc.) communis complex consist of three Northern American species as well as a common Holarctic mosquito (Diptera: Culicidae) Oc. communis (De Geer, 1776). These sister species exhibit important ecological differences and are capable of transmitting various pathogens, but cannot always be differentiated by morphological traits. To investigate the Oc. communis complex in Europe, we compared three molecular markers (COI, ND5 and ITS2) from 54 Estonian mosquitoes as well as two COI marker sequences from Sweden. These sequences were subjected to phylogenetic analysis and screened for Wolbachia Hertig and Wolbach symbionts. Within and between groups, distances were calculated for each marker to better understand the relationships among individuals. Results demonstrate that a group of samples, extracted from adult female mosquitoes matching the morphology of Oc. communis, show a marked difference from the main species when comparing the mitochondrial markers COI and ND5. However, there is no variance between the same specimens when considering the nuclear ITS2. We conclude that Oc. communis encompasses two distinct mitochondrial DNA lineages in the Nordic-Baltic region. Further research is needed to investigate the origin and extent of these genetic differences.
\end{abstract}

Keywords: Ochlerotatus churchillensis; Ochlerotatus nevadensis; Ochlerotatus tahoensis; barcoding; phylogenetics; speciation; vectors

\section{Introduction}

Ochlerotatus (Oc.) communis complex includes four closely related mosquito species [1]: Oc. communis (De Geer, 1776), Oc. churchillensis (Ellis and Burst, 1973), Oc. nevadensis (Chapman and Barr, 1964) and Oc. tahoensis (Dyar, 1916). Morphology-based delimitation of these species is highly problematic due to a lack of reliable distinguishing traits, especially in adults [2]. Thus, researchers have employed both DNA sequencing, using mainly the mitochondrial cytochrome $\mathrm{c}$ oxidase subunit I (COI or COX1), and restriction fragment length polymorphism (RFLP) patterns to help with differentiation [3]. The namesake of the group, Oc. communis, is a common and often numerous Holarctic pest, whereas the other three species appear to be native to Northern America [1]. Due to the ubiquity of Oc. communis and because of its observed morphological variability, it is highly likely that this complex could have additional sister species in other parts of the world besides Northern America [2]. 
The phylogeography of the Oc. communis complex has received relatively little attention. At first these species were distinguished by morphologic as well as morphometric traits and the length differences of select loci, apparent in electrophoresis [1,4]. In 2014, the journal Canadian Entomologist published an article from H. H. Namin et al. describing barcoding (COI) results and designing a new diagnostic RFLP pattern for use with Oc. communis, Oc. churchillensis and Oc. tahoensis [3]. Since that, Oc. churchillensis, Oc. nevadensis and Oc. tahoensis have only been rarely sequenced, for example as part of vector disease investigations [5]. There are more studies on Oc. communis, but this species is still often diagnosed based on morphology alone, although genetic identification is also used [6-10]. Generally speaking, the Oc. communis complex does not currently appear to be under close study.

Mosquitoes from the Oc. communis complex have been associated with many pathogens. The Jamestown Canyon virus has been isolated from North American Oc. communis mosquitoes, which may be one of the species acting as an overwintering reservoir for the pathogen [5]. Oc. communis individuals, in some cases both adults and larva, have been found to carry Sindbis virus (known in Sweden as Ockelbo, in Finland as Pogosta and in Russia as Karelian virus) Batai virus, Francisella (F.) tularensis bacteria as well as different strains of the Inkoo virus in Scandinavian field studies [7,11,12]. Oc. communis could also be one of the main vectors of Dirofilaria repens, a filarial nematode which is currently expanding its area northward $[8,13]$. According to older studies, Oc. communis mosquitoes have also tested positive for Tahyna virus in Russia and six strains of California encephalitis virus in Canada $[14,15]$.

Individuals within a phylogenetic group, even within isomorphic species, can often differ in their medical importance $[16,17]$ and there is a noticeable lack of information regarding how the sister species within Oc. communis complex vary in their vector capacity and competence. Especially as some biological and ecological differences have been observed within the group. Firstly, Oc. churchillensis is the only autogenous species in the group and thought to be non-biting [1]. Both Oc. nevadensis and Oc. tahoensis seem to only be found in mountainous regions, the latter preferring higher elevations, while Oc. churchillensis inhabits forests near the North American tundra [4]. Because of these factors, it has been theorized that the sister species comprising Oc. communis complex may have derived from allopatric as well as sympatric speciation [3].

Maternally inherited Wolbachia Hertig and Wolbach, 1924 symbionts can also contribute to speciation within arthropods. Wolbachia is a genus of cytoplasmically transmitted bacteria that infect the tissues of many arthropods and some nematodes [18,19]. These endosymbionts have shown to cause cytoplasmic incompatibility, parthenogenesis and the death or feminization of biological males (reviewed by Correa and Ballard [20]). Because of this, Wolbachia infections have been seen as possible drivers of microevolution and even speciation [21-23]. Wolbachia strains have been detected in several different mosquito species, but infection rates vary $[24,25]$. At this time, no strains have been found in Oc. communis [8]. However, if detected, it could help explain some genetic results.

A larva with a COI sequence similar but not identical to Oc. tahoensis was recently found in Sweden [7], but the discovery was not further investigated. At the same time, similar cases were found with adult female mosquitoes in Estonia. Taking into account the possibility of additional Oc. communis complex species in Europe [2], a special attention was paid to the recently collected Estonian mosquitoes. The primary aim of this study was to search for a possible novel species within the Oc. communis complex. For this reason, both mitochondrial (mtDNA) and nuclear DNA (nDNA) markers from Nordic-Baltic mosquitoes were analyzed. These samples were also screened for infection with Wolbachia symbionts. Here we present the genetic information of 54 Estonian mosquitoes and compare those to two Swedish samples as well as to reference material from public nucleotide databases.

\section{Materials and Methods}

\subsection{Sampling and Morphological Identification}

This study is based on 54 Estonian mosquitoes and two Swedish COI sequences (Table A1). Of the Estonian individuals, 26 were morphologically identified as Oc. communis, six as Oc. punctor (Kirby, 
1837), eight as Oc. hexodontus (Dyar, 1916), 13 as Oc. cataphylla (Dyar, 1916) and one as Anopheles (An.) messeae (Falleroni, 1926). While Oc. communis is the main focus, Oc. punctor, Oc. hexodontus and Oc. cataphylla samples were included in the analysis to compare how intra- as well as interspecific genetic variation of the Oc. communis complex relates to other common species of the genus Ochlerotatus. An. messeae was used as an outgroup. All Estonian mosquitoes were collected from six different sites during 2015-2016, using automated Mosquito Magnet ${ }^{\circledR}$ Independence (Woodstream Corp., Lititz, PA, USA) machines. Four of these sampling sites were located on the Estonian mainland and two on the largest islands of the country-Saaremaa and Hiiumaa (Figure 1). Insects were stored at $-20{ }^{\circ} \mathrm{C}$ until temporarily thawed and identified under a stereomicroscope Olympus SZ61 (Olympus Corporation, Shinjuku, Tokyo, Japan) to species level, using a standard taxonomic key [2]. Swedish COI sequences originate from Västerbotten County, first from a larva caught in 2014 [7] and the second from an adult female mosquito sent to the Swedish National Veterinary Institute (SVA) in 2017.

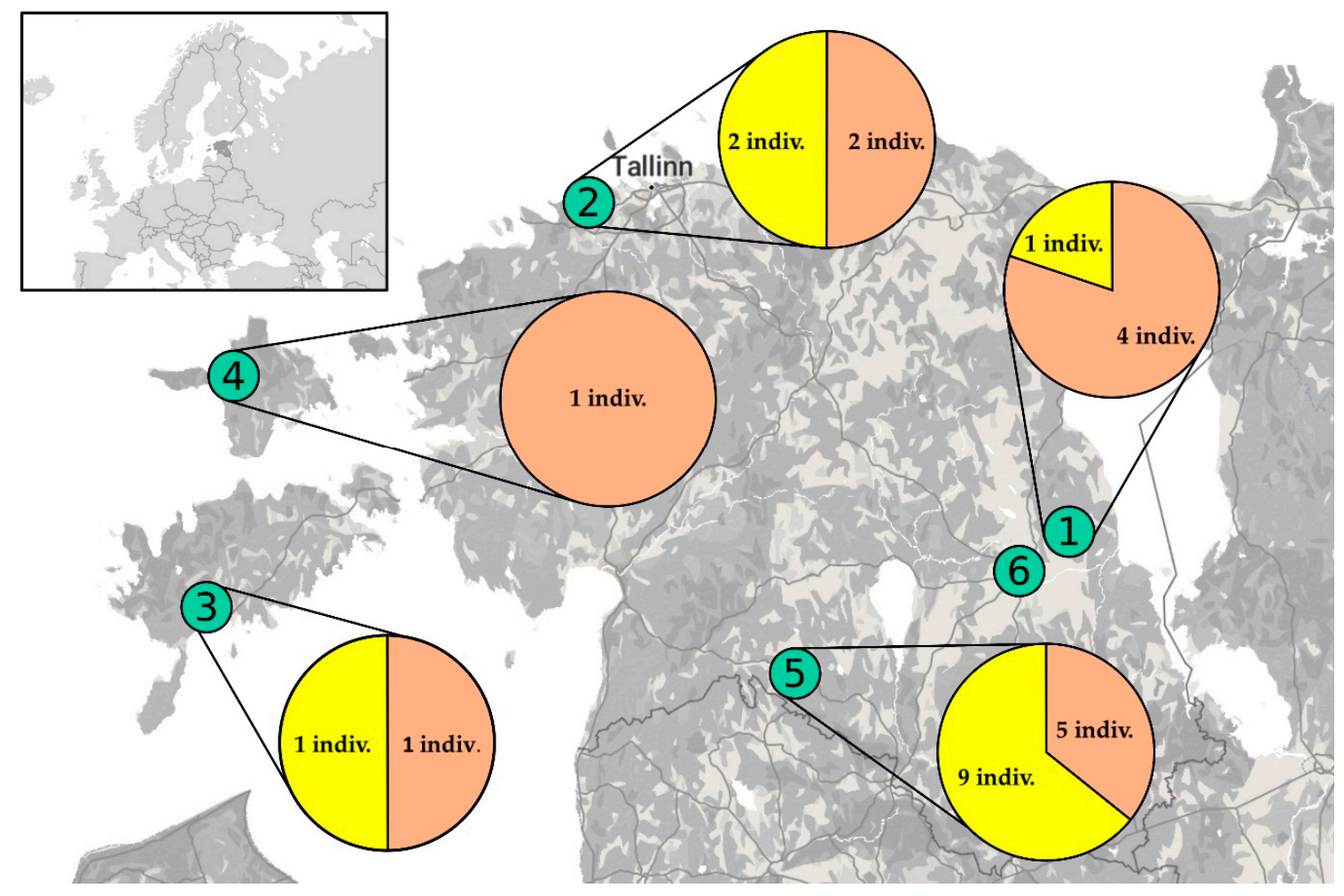

Figure 1. Map showing the six Estonian collection sites, indicated with green circles. Pie charts demonstrate the amount of Oc. sp. (yellow background) and Oc. communis (orange background) specimen caught from each site. In total this paper includes 20 mosquitoes from site 1 "Undi" $\left(58^{\circ} 29^{\prime} \mathrm{N}, 26^{\circ} 54^{\prime} \mathrm{E}\right)$, eight from site 2 "Muraste" $\left(59^{\circ} 28^{\prime} \mathrm{N}, 24^{\circ} 27^{\prime} \mathrm{E}\right)$, four from site 3 "Mändjala" $\left(58^{\circ} 13^{\prime} \mathrm{N}, 22^{\circ} 20^{\prime} \mathrm{E}\right)$, five from site 4 "Vanajõe" $\left(58^{\circ} 53^{\prime} \mathrm{N}, 22^{\circ} 26^{\prime} \mathrm{E}\right), 16$ specimens from site 5 "Metsaküla" and one mosquito from site 6 "Tartu" (58 $04^{\prime} \mathrm{N}, 25^{\circ} 31^{\prime}$ E). 31 of these mosquitoes were caught in 2015 and 23 during 2016. Base map curtesy of @OOpenStreetMap contributors (https: //www.openstreetmap.org/copyright) and @MapTiler (https://www.maptiler.com/copyright/).

\subsection{DNA Extraction}

DNA was extracted from the Estonian mosquitoes using either DNeasy Blood and Tissue Kit (Qiagen, Hilden, North Rhine-Westphalia, Germany) or PrepMan ${ }^{\circledR}$ Ultra Sample Preparation Reagent (Thermo Fisher Scientific Inc., Waltham, Massachusetts, USA). There were no qualitative differences between the used DNA extraction methods. Whole mosquitoes were used for the DNeasy Blood and Tissue Kit, while three legs from each specimen were taken for extracting DNA with the PrepMan ${ }^{\circledR}$ Ultra Sample Preparation Reagent. DNeasy Blood and Tissue Kit was used in accordance with the 
manufacturers manual and the DNA extractions made with PrepMan ${ }^{\circledR}$ Ultra Sample Preparation Reagent were conducted as specified in previous work [26].

\subsection{DNA Markers}

Two protein coding mitochondrial and two nuclear markers were amplified and sequenced from all Estonian mosquitoes used in this study. However, only three markers were used for further analysis as the D2 region of the large subunit $28 \mathrm{~S}$ rDNA gene was too conserved between Ochlerotatus species to be of use, although it has been successfully utilized for species identification in other mosquito genera $[27,28]$. The $5^{\prime}$ region of the cytochrome c oxidase (COI) subunit I was chosen as one of the markers for its widespread use in mosquito identification and its generally good ability to differentiate between species, although it can at times either over- or underestimate the true number of well distinguished monophyletic groups $[16,29,30]$. The nicotinamide adenine dinucleotide (NADH) dehydrogenase subunit 5 (ND5) gene was used as an additional mitochondrial marker. ND5 is generally thought to have faster evolution rates compared to COI and thus has been used for inter- as well as intraspecies studies in mosquitoes [31-33]. Finally, the nuclear internal transcribed spacer 2 (ITS2), a region of the ribosomal RNA gene, was used as the most conserved marker. ITS2 sequences have been used for species identification in many animal groups and may be the most used nDNA marker for mosquitoes [16,34,35]. It has generally been proposed as a good marker to analyze alongside COI [16].

Each mosquito sample was also screened for Wolbachia symbionts by amplifying part of the Wolbachia surface protein (WSP) gene.

\subsection{Primers}

For COI, which is by far the most commonly sequenced marker for mosquitoes, we used the universal primers LCO1490 (5'-GGTCAACAAATCATAAAGATATTG G-3') and HCO2198 (5'-TAAACTTCAGGGTGACCAAAAAATCA-3'), that consistently resulted in 710 bp long sequences [36]. A $450 \mathrm{bp}$ segment of the ND5 region was amplified and sequenced using the primers 6500 (5'-TCCTTAGAATAAAATCCCGC-3') and 7398 (5'-GTTTCTGCTTTAGTTCATTCTTC-3') which were originally designed for Aedes (Ae.) albopictus [37]. Primer pair 5.8S (5'-TGTGAACTG CAGGACACATG-3') and 28S (5'-ATGCTTAAATTTAGGGGGTA-3') was used for ITS2, producing approximately $368 \mathrm{bp}$ to $387 \mathrm{bp}$ long sequences [38]. The ITS2 primers were initially developed to differentiate between cryptic Anopheline mosquitoes, but can be used for other mosquito genera as well. DNA from the Wolbachia symbionts WSP gene was amplified with the primers wsp 81F (5'-TGGTCCAATAAGTGATGAAGAAAC-3') and wsp 691R (5'-AAAAATTAAACGCTACTCCA-3') that would have resulted in 600 bp sequences [39].

\subsection{Polymerase Chain Reaction (PCR) and Sequencing}

While the composition of the polymerase chain reaction (PCR) mixes remained the same throughout, thermal cycler programs were adjusted for each primer pair to maximize the amplification yield of the respective marker regions. All PCR reactions contained 12.5 $\mu \mathrm{L}$ DreamTaq DNA Polymerase Master Mix (2X) (Thermo Fisher Scientific Inc., Waltham, MA, USA), $0.4 \mu \mathrm{M}$ of each primer $(0.04 \mu \mathrm{mol}$, TAG Copenhagen, Frederiksberg, Denmark), $10.5 \mu \mathrm{L}$ nuclease-free water and $1 \mu \mathrm{L}$ DNA template. The PCR program for amplifying the COI marker region was as follows: $95^{\circ} \mathrm{C}$ for $2 \mathrm{~min} 15 \mathrm{~s}$, followed by 35 cycles of $95^{\circ} \mathrm{C}$ for $30 \mathrm{~s}, 57^{\circ} \mathrm{C}$ for $45 \mathrm{~s}, 72{ }^{\circ} \mathrm{C}$ for $45 \mathrm{~s}$ and a final elongation step at $72{ }^{\circ} \mathrm{C}$ for $5 \mathrm{~min}$. Although mostly identical, the PCR program for the ITS2 sequence introduced a much lower annealing temperature: $95{ }^{\circ} \mathrm{C}$ for $2 \mathrm{~min} 15 \mathrm{~s}, 35$ cycles of $95{ }^{\circ} \mathrm{C}$ for $30 \mathrm{~s}, 45{ }^{\circ} \mathrm{C}$ for $45 \mathrm{~s}, 72{ }^{\circ} \mathrm{C}$ for $45 \mathrm{~s}$ and an elongation at $72{ }^{\circ} \mathrm{C}$ for $5 \mathrm{~min}$. On the other hand, amplifying the mitochondrial ND5 region required a much longer PCR program, which contained 2 different sets of cycles on low annealing temperatures. The final program was: $94^{\circ} \mathrm{C}$ for 3 min denaturation followed by 10 cycles of $94{ }^{\circ} \mathrm{C}$ for $30 \mathrm{~s}, 38^{\circ} \mathrm{C}$ for $30 \mathrm{~s}, 65^{\circ} \mathrm{C}$ for $45 \mathrm{~s}$, then 50 cycles of $94^{\circ} \mathrm{C}$ for $30 \mathrm{~s}, 38^{\circ} \mathrm{C}$ for $30 \mathrm{~s}, 65^{\circ} \mathrm{C}$ for $45 \mathrm{~s}$ and a last elongation of $65^{\circ} \mathrm{C}$ for $3 \mathrm{~min}$. The WSP region of the symbiont was amplified using a previously published PCR 
program [24] and a positive control sample from Culex pipiens was also added to the PCR. All samples were amplified with ESCO Swift Maxi Thermal Cycler (ESCO Micro Pte. Ltd., Changi South Street, Singapore, Singapore).

PCR products were checked for signals by electrophoresis using $1.6 \%$ agarose gel infused with ethidium bromide. Amplified samples were tinted with DNA Gel Loading Dye (6X) (Thermo Fisher Scientific Inc., Waltham, MA, USA) prior to electrophoresis. Positive signals were compared to GeneRuler 100 bp DNA Ladder, ready-to-use (Thermo Fisher Scientific Inc., Waltham, MA, USA) or, in the case of the WSP samples, to the GeneRuler 100 bp Plus DNA Ladder, ready-to-use (same company) to visually determine the approximate lengths of the replicated DNA strands. PCR products were cleaned and sequenced with Applied Biosystems 3130xl Genetic Analyzer by a two-directional procedure (Thermo Fisher Scientific Inc., Waltham, MA, USA).

\subsection{Sequence Analysis}

Forward and reverse DNA strands were aligned and assembled into consensus sequences in BioEdit Sequence Alignment Editor version 7.2.5 [40]. Primers and low-quality areas were trimmed to produce the final sequences. MEGA $X$ version 10.0.5 [41] was used for sequence alignment and data analysis. All original DNA sequences were uploaded to the online database GenBank. Reference sequences were added to the analysis via the Blast Search tool in MEGA X (Table A2). This was effective for COI and ITS2 markers. However, the mtDNA marker ND5 has so far received little attention in mosquitoes from the Ochlerotatus genus and, therefore, no previous sequences could be found from the database.

Protein-coding gene sequences were aligned based on codons, whereas the DNA strands for ITS2 were aligned by nucleotides alone and allowed gaps for indels. In all cases, the Multiple Sequence Comparison by Log-Expectation (MUSCEL) tool with default options was used for aligning sequences. The Find Best-Fit Substitution Model feature was used for all of the analyzed markers to determine the most appropriate model and Rates among Sites variable. These results were then used to calculate mean within and between group genetic distances measuring the proportion of nucleotide sites with differences between each sequence pair (p-distances). This was done using the Compute within Group Mean Distance and Compute between Group Mean Distance functions in MEGAX. Gaps/Missing Data Treatment was set to complete deletion, which ensured that all sequences of the same marker were trimmed to identical lengths: $441 \mathrm{bp}$ for COI, $321 \mathrm{bp}$ for ND5 and $251 \mathrm{bp}$ for the ITS2 marker region.

Phylogenetic trees were constructed with the maximum likelihood method, while also using the analysis model and Rates among Sites recommended by the Find Best-Fit Substitution Model feature. The Gamma Parameter $(+\mathrm{G})$ was set to 6, Gaps/Missing Data Treatment was set to complete deletion and Bootstrap with 1000 replications was employed each time. All trees were annotated and rooted using An. messeae as an outgroup. Trees were then modified to only display bootstrap values $>75 \%$ and distance values $\geq 0.01$. Differences between population sizes were not accounted for. While Oc. communis, Oc. punctor and Oc. cataphylla are all common in Estonia, there is very little information about their exact effective population sizes. However, mosquitoes of the Oc. sp. group likely have a much smaller effective population size than the normal type Oc. communis.

\section{Results}

Of the 54 Estonian mosquitoes used in this study, 26 were identified as Oc. communis by morphological evaluation, but only 14 of these were grouped together by all three DNA markers. The remaining 12 individuals formed a separate monophyletic group within the Oc. communis complex based to their mitochondrial markers, similarly to two COI sequences received from Sweden. However, this pattern was not apparent when examining the nDNA results.

According to the phylogenetic tree based on the COI marker (Figure 2), 12 sequences from mosquitoes caught at three different sites (sites 1,2 and 5) in Estonia (Figure 1) and 2 sequences from Sweden cluster together (hereafter referred to as Oc. sp.), distinct from Oc. communis and closer to the 
North American species Oc. tahoensis and Oc. churchillensis. In fact, there is on average about 0.063 (standard error (S.E) 0.018) substitutions per base difference between Oc. communis specimens and the Oc. sp. group. Meanwhile, the p-distances between Oc. sp. individuals and Oc. tahoensis as well as Oc. churchillensis are smaller, 0.046 (S.E. 0.013) and 0.054 (S.E. 0.015) respectively. It should also be noted, that the Oc. sp. COI sequences show a high similarity to each other, being almost genetically identical. This is in contrast to the larger genetic diversity within other groups. These results show that there is a previously unknown group of genetically distinct individuals belonging to the Oc. communis complex found in Europe.

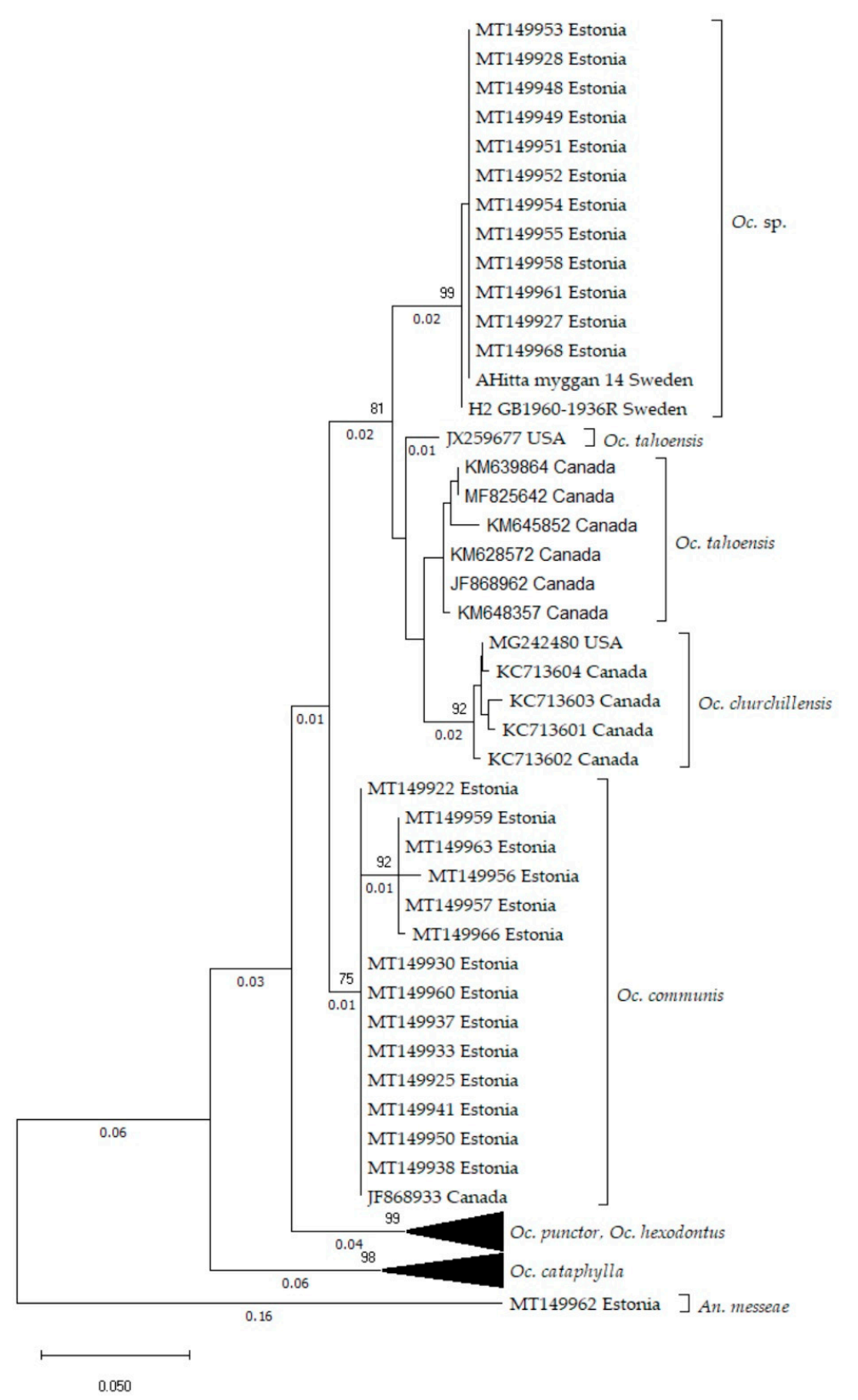

Figure 2. Phylogenetic tree based on 72 partial cytochrome c oxidase (COI) sequences (441). Calculated with the Maximum Likelihood method, using Tamura 3-parameter [42] model, with discrete gamma distribution $(6$ categories $(+\mathrm{G}$, parameter $=0.1790)$ ) Branch lengths are shown to scale and measured as the number of substitutions per site. An. messeae was used as an outgroup for rooting the tree. Oc. sp. sequences are genetically closer to North American species Oc. tahoensis and Oc. churchillensis than the widespread Oc. communis. 
The ND5 marker region also suggests that mosquitoes forming the Oc. sp. group are a distinct genetic unit, separate from traditional Oc. communis mtDNA sequences (Figure 3). Compared to the COI region, the ND5 marker sequences are even more variable between groups. Between Oc. communis and the Oc. sp. cluster, there is a difference of on average 0.083 (S.E 0.031) base substitutions per site. Yet, within group average evolutionary distances remain small. In the Oc. sp. group, there are only on average 0.001 (S.E 0.001) base substitutions per site over all of the sequence. The p-distance is once again larger among the traditional Oc. communis samples, averaging 0.008 (S.E 0.009) base substitutions. ND5 marker sequences associated with Oc. punctor, Oc. hexodontus and Oc. cataphylla clusters are even more variable. Unfortunately, there are no ND5 marker sequences from Oc. tahoensis, Oc. churchillensis or Oc. nevadensis currently available in GenBank. Likewise, because the ND5 region is a less popular marker than COI and ITS2, there were also no reference sequences for Oc. communis, Oc. punctor, Oc. hexodontus or Oc. cataphylla. However, the ND5 sequences included in this study support the conclusions drawn from the COI marker.

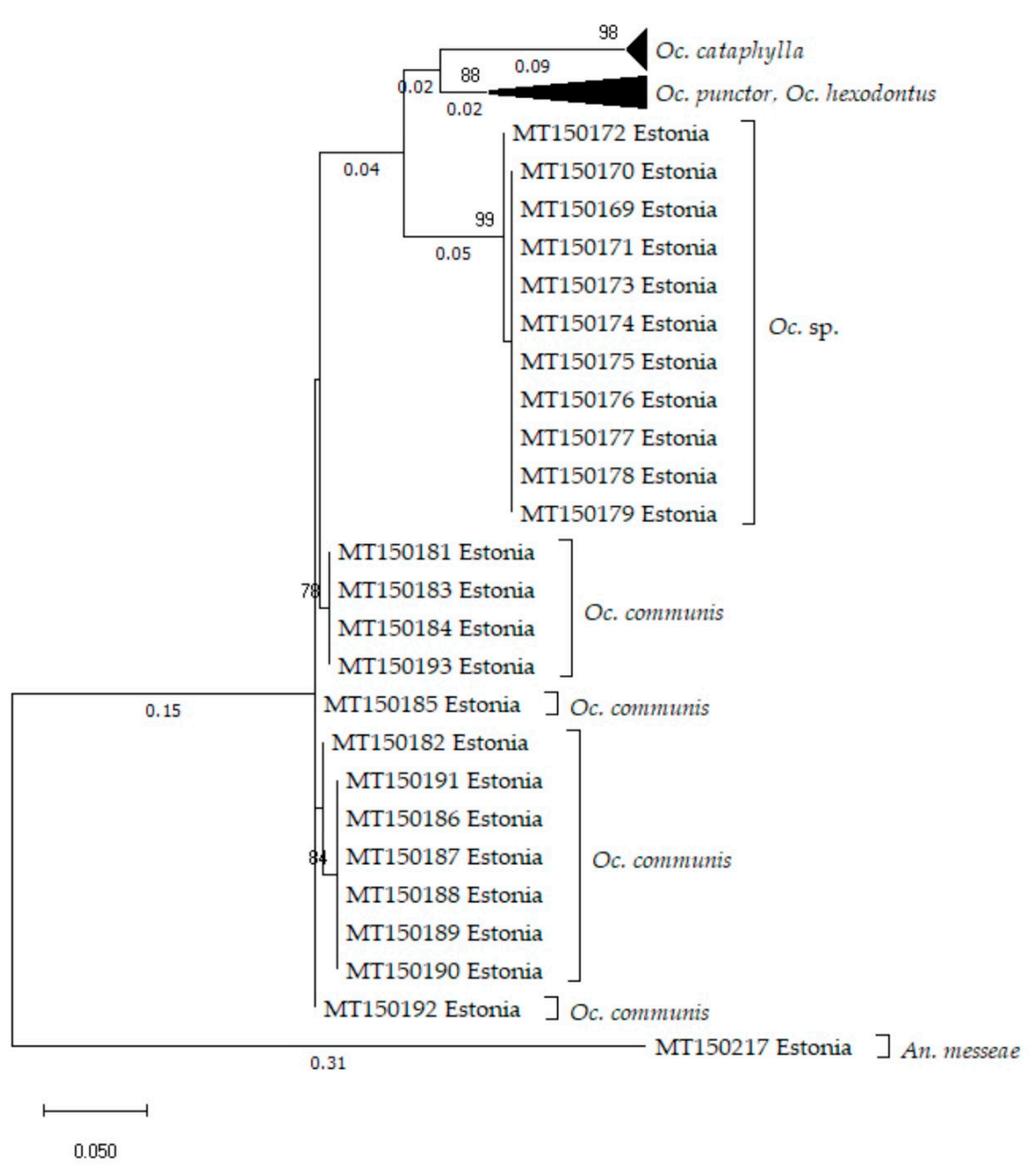

Figure 3. Phylogenetic tree representing the information of 48 dehydrogenase subunit 5 (ND5) marker region sequences $(321 \mathrm{bp})$. The tree is calculated with the maximum likelihood method, using the Tamura 3-parameter [42] model and a discrete gamma distribution (6 categories $(+G$, parameter $=0.1516)$ ). Branch lengths are shown to scale and measured based on the average number of substitutions per site between sequence pairs. An. messeae was used the outgroup in order to root the tree. Oc. sp. sequences cluster together, away from the Oc. communis group.

While mitochondrial markers outlined Oc. sp. group as a separate entity, this is not the case for the nuclear marker ITS2. In fact, there are no differences between the ITS2 sequences from Oc. communis and the Oc. sp. samples (Figure 4). On the other hand, Oc. churchillensis reference 
sequences downloaded from GenBank maintain their genetic distance from Oc. communis, being on average 0.025 (S.E. 0.009) substitutions per base apart. The same is true for Oc. punctor, Oc. hexodontus and Oc. cataphylla clusters, which differ on average from the Oc. communis group by 0.035 (S.E 0.011) and 0.079 (S.E 0.017) base substitutions per site, respectively. It should also be noted that the ITS2 sequences of the Oc. communis cluster have no notable within-group genetic variance. Within group average genetic variance is also relatively low in other groups. From these results we can see that the ITS2 region of Estonian Oc. communis individuals is quite conserved and does not echo the variance shown by the mtDNA markers.

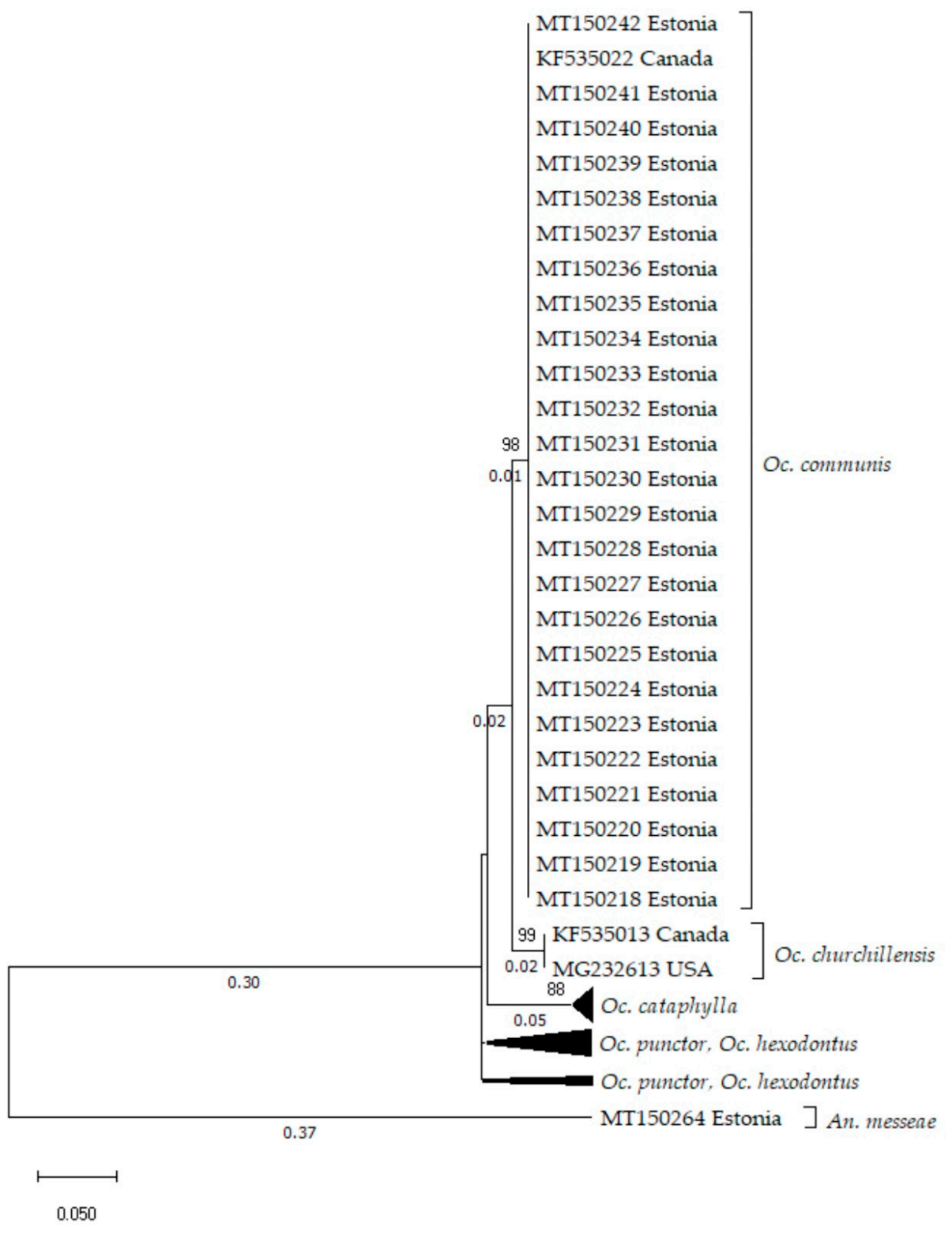

Figure 4. Phylogenetic tree based on the 53 internal transcribed spacer 2 (ITS2) marker sequences (251 bp). Calculated with the maximum likelihood method, using the Kimura 2-parameter model [43] and discrete Gamma distribution $(6$ categories $(+G$, parameter $=0.8737)$ ). Branch lengths are shown to scale and measured based on the average number of substitutions per site between sequence pairs. An. messeae was used as the outgroup for rooting the tree. There appears to be no variation amid the ITS2 sequences Oc. sp. sequences and Oc. communis. However, Oc. churchillensis sequences obtained from GenBank remain as a separate group. 
Estonian mosquito samples were screened for Wolbachia surface protein as it could offer an explanation for the divergent mtDNA lineage within the analyzed Oc. communis individuals. However, there were no positive electrophoresis signals for any of the samples except for the positive control. Therefore, there is no evidence of Wolbachia symbionts in the Oc. communis individuals used in this study.

\section{Discussion}

There is a discrepancy between the mtDNA and nDNA markers among mosquitoes morphologically identified as Oc. communis in the Nordic-Baltic region. The mitochondrial markers COI and ND5 clearly distinguish two clusters of individuals within the Oc. communis complex: One identical to Oc. communis reference sequences and the other representing a new group. However, this difference is not reflected in the ITS2 sequences of the same mosquitoes. Based on the nuclear marker, all examined Oc. communis-like individuals have identical ITS2 marker sequences, whereas reference sequences for Oc. churchillensis, which also belongs to the Oc. communis complex, remain distinct from Oc. communis. There appears to be a previously unreported mtDNA lineage within the Nordic-Baltic Oc. communis populations, but no variance within the nDNA to point to a distinct species.

Both COI and ND5 marker regions have high support for similar monophyletic clades and both trees show some amount of nucleotide changes between traditional Oc. communis individuals, while Oc. sp. sequences are largely identical. This shows, that the $O c$. sp. clade is evolutionarily younger than the traditional Oc. communis and its members probably less numerous, as the mtDNA of this group has yet to accrue many mutations [44]. However, the nuclear marker ITS2 shows noticeably less divergence between all of the analyzed Ochlerotatus species. Moreover, the D2 region of the large subunit 28S, also originally sequenced for this study, was unable to provide any notable differences within Ochlerotatus, although it has been shown to work for anopheline mosquitoes [28]. It seems that the species analyzed for this study are in general more closely related to each other than those most often sequenced in other mosquito genera. Therefore, it is currently difficult to say if any of the markers used in this work might underestimate the true diversity of the Ochlerotatus species. This matter would be greatly improved by finding and analyzing nDNA markers with better resolution for the Ochlerotatus genus. It would also be useful to sequence a larger number of Oc. communis, in order to obtain a better overview of its natural intraspecific variance.

The reason for mitochondrial differences between coexisting groups can be hard to pinpoint. As the common type Oc. communis and the individuals with differing mtDNA coexist in the same communities and have identical ITS2 sequences, it is probable that they are intermixing. MtDNA variation in arthropod populations can be influenced by symbiotic bacteria like the maternally inherited Wolbachia [45]. However, none of the samples used in this study were positive for Wolbachia DNA and this coincides with previous observations [8]. There could be other speciation-driving factors in play, but that is impossible to determine at this juncture. Importantly, the fauna of the Nordic-Baltic region is relatively young, only emerging after the Last Glacial Period more than 9000 years ago when it was recolonized by organisms from different glacial refugiums [46-48]. It is possible that Eurasian Oc. communis complex individuals with the differing mtDNA used to be geographically separated, but not genetically different enough as to have evolved reproductive barriers.

Uncertainties in mtDNA sequencing results can also be caused by pseudogenes or heteroplasmy. Many organisms are known to have nuclear insertions of mitochondrial sequences (NuMts) as well as multiple types of functional mtDNA in the same individual (heteroplasmy) - both of these can interfere with the amplification and sequencing of mitochondrial markers, resulting in erroneous conclusions if not recognized [49]. Sequences from COI and ND5 genes have been known to be incorporated into nDNA as NuMts [50]. Furthermore, starting with Aedes aegypti (Linnaeus, 1762) and Culex quinquefasciatus (Say, 1823), NuMts have now been found in many mosquito species [51,52]. However, these insertions in nDNA are non-functional and, therefore, not under the same constraints or mutation rates as the real mtDNA $[53,54]$. These pseudogenes tend to contain inappropriate stop-codons and indels as well as more point mutation than normal $[49,55]$. Such problems are not 
evident in the sequences analyzed in this study. Heteroplasmy can also result in ambiguous reads in Sanger sequencing, but can be harder to identify compared to NuMts [16]. It cannot be completely ruled out that the less common Oc. communis mtDNA lineage reported in this study is a sign of heteroplasmy.

While Oc. communis is not currently considered an important disease vector, it has been indicated as a possible carrier of several viral and bacterial pathogens. This species is known for its wide distribution and can be numerous at times [2]. Because of this, genetic deviations within Oc. communis populations may be important from future vector and pest control standpoints. Estonian and Swedish faunas are relatively young and it is reasonable to assume that Oc. communis individuals carrying the different mtDNA variant are not limited to the Nordic-Baltic region, but can be found within a much wider area. However, there has thus far been little indication of notable genetic discrepancies within this species in Central and Western Europe. Because of this, more sampling efforts should be directed towards Eastern Eurasia. Also, there is more work to be done in regards to sequencing additional nDNA markers from Oc. communis complex species and finding more informative nDNA markers to use with genus Ochlerotatus in general.

\section{Conclusions}

The current study presents evidence for an additional discrete mtDNA lineage within Oc. communis in Europe. This common Holarctic pest is the namesake of the Oc. communis complex, which it shares with three closely related Northern American species. While these sister species have sometimes been regarded as subspecies to Oc. communis, there are clear differences in their ecology, genetic material and in some cases morphology. It has been long theorized that there could be more species belonging to the Oc. communis complex in other parts of the world besides Northern America. In this study we show, based on the COI and ND5 markers, that there is a group of Oc. sp. individuals with a distinct mtDNA lineage within morphologically identified Oc. communis mosquitoes in Estonia and Sweden. We also show that these differences are not apparent in the nDNA of the same individuals. It was also determined that the analyzed mosquitoes had no detectable Wolbachia infection, ruling these maternally inherited symbionts out as a possible explanation for the mitochondrial differences.

Author Contributions: Conceptualization, H.K., L.T. and O.K.; Data curation, H.K.; Formal analysis, H.K. and T.L.; Funding acquisition, L.T. and O.K.; Investigation, H.K. and T.L.; Methodology, H.K., L.T., T.L. and O.K.; Project administration, L.T. and O.K.; Supervision, L.T. and O.K.; Validation, H.K.; Visualization, H.K.; Writing-original draft, H.K.; Writing-review and editing, H.K., L.T., T.L. and O.K. All authors have made notable contributions to this study as well as have read and agreed to the published version of the manuscript.

Funding: This study was supported by institutional research funding IUT21-1 of the Estonian Research Council and by Estonian University of Life Sciences research and development project 8P160014VLVP.

Acknowledgments: The authors would like to especially thank Magnus Evander (Umeå University, Sweden) for providing the COI sequence H2_GB1960-1936R from Västerbotten County, Sweden and Erkki Ounap (Tartu University, Estonia) for guidance in phylogenetic analyses. We are also grateful to everyone involved in maintaining and operating insect traps.

Conflicts of Interest: The authors declare no conflict of interest. The funders had no role in the design of the study; in the collection, analyses, or interpretation of data; in the writing of the manuscript; or in the decision to publish the results. 


\section{Appendix A}

Table A1. Mosquitoes used in this study with their GenBank sequence numbers and upload year where possible as well as the country of origin.

\begin{tabular}{|c|c|c|c|c|c|c|c|}
\hline ID & $\begin{array}{l}\text { Site } \\
\text { No. }\end{array}$ & $\begin{array}{l}\text { Morphologically } \\
\text { Determined } \\
\text { Species }\end{array}$ & $\begin{array}{l}\text { Country } \\
\text { of Origin }\end{array}$ & $\begin{array}{c}\text { GenBank } \\
\text { COI Acc. } \\
\text { Num. }\end{array}$ & $\begin{array}{c}\text { GenBank } \\
\text { ND5 Acc. } \\
\text { Num. }\end{array}$ & $\begin{array}{c}\text { GenBank } \\
\text { ITS2 Acc. } \\
\text { Num. }\end{array}$ & $\begin{array}{l}\text { Upload } \\
\text { Year }\end{array}$ \\
\hline 15004012 & 1 & Oc. hexodontus & Estonia & MT149916 & MT150197 & MT150247 & 2020 \\
\hline 15004015 & 1 & Oc. cataphylla & Estonia & MT149946 & MT150204 & MT150252 & 2020 \\
\hline 15005002 & 1 & Oc. punctor & Estonia & MT149917 & MT150196 & - & 2020 \\
\hline 15005005 & 1 & Oc.punctor & Estonia & MT149918 & - & - & 2020 \\
\hline 15005007 & 1 & Oc. hexodontus & Estonia & MT149919 & MT150198 & - & 2020 \\
\hline 15005008 & 1 & Oc. cataphylla & Estonia & MT149920 & MT150205 & MT150253 & 2020 \\
\hline 15005010 & 1 & Oc. cataphylla & Estonia & MT149921 & MT150206 & MT150254 & 2020 \\
\hline 15005012 & 1 & Oc. communis & Estonia & MT149922 & MT150192 & MT150230 & 2020 \\
\hline 15009025 & 2 & Oc. cataphylla & Estonia & MT149923 & MT150207 & MT150255 & 2020 \\
\hline 15009026 & 2 & Oc. cataphylla & Estonia & MT149924 & MT150208 & - & 2020 \\
\hline 15009027 & 2 & Oc. communis & Estonia & MT149925 & MT150184 & MT150221 & 2020 \\
\hline 15009028 & 2 & Oc. punctor & Estonia & MT149926 & MT150195 & MT150243 & 2020 \\
\hline 15009030 & 2 & Oc. sp. & Estonia & MT149927 & MT150171 & MT150234 & 2020 \\
\hline 15009031 & 2 & Oc. sp. & Estonia & MT149928 & MT150172 & MT150235 & 2020 \\
\hline 15009036 & 2 & Oc. hexodontus & Estonia & MT149929 & MT150199 & MT150248 & 2020 \\
\hline 15010004 & 2 & Oc. communis & Estonia & MT149930 & MT150185 & MT150222 & 2020 \\
\hline 15013001 & 1 & Oc. cataphylla & Estonia & MT149931 & MT150209 & MT150256 & 2020 \\
\hline 15013003 & 1 & Oc. cataphylla & Estonia & MT149932 & MT150210 & MT150257 & 2020 \\
\hline 15013004 & 1 & Oc. communis & Estonia & MT149933 & MT150183 & MT150220 & 2020 \\
\hline 15013005 & 1 & Oc. cataphylla & Estonia & MT149934 & MT150211 & MT150258 & 2020 \\
\hline 15013006 & 1 & Oc. punctor & Estonia & MT149935 & MT150194 & - & 2020 \\
\hline 15013015 & 1 & Oc. cataphylla & Estonia & MT149936 & MT150212 & MT150259 & 2020 \\
\hline 15016024 & 3 & Oc. communis & Estonia & MT149937 & MT150182 & MT150219 & 2020 \\
\hline 15016030 & 3 & Oc. communis & Estonia & MT149938 & MT150181 & MT150218 & 2020 \\
\hline 15016041 & 3 & Oc. hexodontus & Estonia & MT149939 & MT150200 & MT150249 & 2020 \\
\hline 15018001 & 4 & Oc. hexodontus & Estonia & MT149940 & - & MT150245 & 2020 \\
\hline 15018007 & 4 & Oc. communis & Estonia & MT149941 & MT150186 & MT150223 & 2020 \\
\hline 15018008 & 4 & Oc. hexodontus & Estonia & MT149942 & - & MT150246 & 2020 \\
\hline 15018011 & 4 & Oc. punctor & Estonia & MT149943 & - & MT150244 & 2020 \\
\hline 15020002 & 3 & Oc. cataphylla & Estonia & MT149944 & MT150213 & MT150260 & 2020 \\
\hline 15032002 & 4 & Oc. cataphylla & Estonia & MT149945 & MT150214 & MT150261 & 2020 \\
\hline 16008001 & 6 & Oc. cataphylla & Estonia & MT149947 & MT150215 & MT150262 & 2020 \\
\hline 16079095 & 5 & Oc. sp. & Estonia & MT149948 & MT150173 & MT150236 & 2020 \\
\hline 16079097 & 5 & Oc. sp. & Estonia & MT149949 & MT150169 & MT150232 & 2020 \\
\hline 16079102 & 5 & Oc. communis & Estonia & MT149950 & - & MT150224 & 2020 \\
\hline 16079110 & 5 & Oc. sp. & Estonia & MT149951 & MT150170 & MT150233 & 2020 \\
\hline 16079112 & 5 & Oc. sp. & Estonia & MT149952 & MT150174 & MT150237 & 2020 \\
\hline 16079120 & 5 & Oc. sp. & Estonia & MT149953 & MT150175 & MT150238 & 2020 \\
\hline 16142001 & 5 & Oc. sp. & Estonia & MT149954 & MT150176 & MT150239 & 2020 \\
\hline 16142002 & 5 & Oc. sp. & Estonia & MT149955 & MT150177 & MT150240 & 2020 \\
\hline 16142005 & 5 & Oc. cataphylla & Estonia & MT149969 & MT150216 & MT150263 & 2020 \\
\hline 16142006 & 5 & Oc. communis & Estonia & MT149956 & MT150187 & MT150225 & 2020 \\
\hline 16142007 & 5 & Oc. communis & Estonia & MT149957 & MT150188 & MT150226 & 2020 \\
\hline 16142010 & 5 & Oc. sp. & Estonia & MT149958 & MT150178 & MT150241 & 2020 \\
\hline 16142013 & 5 & Oc. communis & Estonia & MT149959 & MT150189 & MT150227 & 2020 \\
\hline 16142016 & 5 & Oc. communis & Estonia & MT149960 & MT150193 & MT150231 & 2020 \\
\hline 16142023 & 5 & Oc. sp. & Estonia & MT149961 & MT150179 & MT150242 & 2020 \\
\hline 16142040 & 5 & An. messeae & Estonia & MT149962 & MT150217 & MT150264 & 2020 \\
\hline 16149001 & 1 & Oc. communis & Estonia & MT149963 & MT150190 & MT150228 & 2020 \\
\hline 16149003 & 1 & Oc. hexodontus & Estonia & MT149964 & MT150202 & MT150250 & 2020 \\
\hline 16149004 & 1 & Oc. punctor & Estonia & MT149965 & MT150203 & - & 2020 \\
\hline 16149006 & 1 & Oc. communis & Estonia & MT149966 & MT150191 & MT150229 & 2020 \\
\hline 16149007 & 1 & Oc. hexodontus & Estonia & MT149967 & MT150201 & MT150251 & 2020 \\
\hline 16149009 & 1 & Oc. sp. & Estonia & MT149968 & - & - & 2020 \\
\hline H2_GB1960-1936R & - & N/A & Sweden & - & - & - & - \\
\hline hitta_myggan_14 & - & $\mathrm{N} / \mathrm{A}$ & Sweden & - & - & - & - \\
\hline
\end{tabular}


Table A2. GenBank reference sequences used in the phylogenetic analysis, selected based on their similarity to the Swedish and Estonian mosquito sequences.

\begin{tabular}{cccccc}
\hline Species & $\begin{array}{c}\text { Country of } \\
\text { Origin }\end{array}$ & $\begin{array}{c}\text { GenBank COI } \\
\text { Acc. Num. }\end{array}$ & $\begin{array}{c}\text { GenBank ND5 } \\
\text { Acc. Num. }\end{array}$ & $\begin{array}{c}\text { GenBank ITS2 } \\
\text { Acc. Num. }\end{array}$ & $\begin{array}{c}\text { Upload } \\
\text { Year }\end{array}$ \\
\hline Oc. tahoensis & USA & JX259677 & - & - & 2012 \\
Oc. churchillensis & USA & MG242480 & - & - & 2018 \\
Oc. tahoensis & Canada & JF868962 & - & - & 2018 \\
Oc. communis & Canada & JF868933 & - & - & 2018 \\
Oc. punctor & Belgium & KM258280 & - & - & 2015 \\
Oc. hexodontus & Canada & KR697054 & - & - & 2018 \\
Oc. cataphylla & Sweden & KP942759 & - & - & 2018 \\
Oc. tahoensis & Canada & KM648357 & - & - & 2019 \\
Oc. tahoensis & Canada & KM628572 & - & - & 2019 \\
Oc. churchillensis & Canada & KC713604 & - & - & 2013 \\
Oc. tahoensis & Canada & MF825642 & - & - & 2018 \\
Oc. tahoensis & Canada & KM645852 & - & - & 2019 \\
Oc. tahoensis & Canada & KM639864 & - & - & 2019 \\
Oc. churchillensis & Canada & KC713602 & - & - & 2013 \\
Oc. churchillensis & Canada & KC713603 & - & - & 2013 \\
Oc. churchillensis & Canada & KC713601 & - & - & 2013 \\
Oc. communis & Canada & - & - & KF535022 & 2013 \\
Oc. churchillensis & Canada & - & KF535013 & 2013 \\
Oc. churchillensis & USA & - & - & KG232613 & 2018 \\
Oc. punctor & Canada & - & - & KF535072 & 2013 \\
Oc. hexodontus & Canada & - & - & KF535026 & 2013 \\
Oc. abserratus & Canada & - & - & & 2013 \\
\hline
\end{tabular}

\section{References}

1. Brust, R.A.; Munstermann, L.E. Morphological and Genetic Characterization of the Aedes (Ochlerotatus) communis Complex (Diptera: Culicidae) in North America. Ann. Entomol. Soc. Am. 1992, 85, 1-10. [CrossRef]

2. Becker, N.; Petric, D.; Zgomba, M.; Boase, C.; Madon, M.; Dahl, C.; Kaiser, A. Mosquitoes and Their Control, 2nd ed.; Springer Science \& Business Media: Heidelberg, Germany, 2010.

3. Namin, H.H.; Iranpour, M.; Sharanowski, B.J. Phylogenetics and Molecular Identification of the Ochlerotatus communis Complex (Diptera: Culicidae) Using DNA Barcoding and Polymerase Chain Reaction-Restriction Fragment Length Polymorphism. Can. Entomol. 2013, 146, 26-35. [CrossRef]

4. Ellis, R.A.; Brust, R.A. Sibling Species Delimitation in the Aedes communis (Degeer) Aggregate (Diptera: Culicidae). Can. J. Zool. 1973, 51, 915-959. [CrossRef]

5. Andreadis, T.G.; Anderson, J.F.; Armstrong, P.M.; Main, A.J. Isolations of Jamestown Canyon Virus (Bunyaviridae: Orthobunyavirus) from Field-Collected Mosquitoes (Diptera: Culicidae) in Connecticut, USA: A ten-year analysis, 1997-2006. Vector-Borne Zoonotic Dis. 2008, 8, 175-188. [CrossRef]

6. Andreeva, Y.V.; Khrabrova, N.V.; Simakova, A.V.; Sibataeva, A.M.; Sibataev, A.K. Species Diversity of Blood-Sucking Mosquitoes (Diptera: Culicidae) in Tomsk Region. Int. J. Environ. Stud. 2017, 74, 782-789. [CrossRef]

7. Tingström, O.; Wesula Lwande, O.; Näslund, J.; Spyckerelle, I.; Engdahl, C.; Von Schoenberg, P.; Ahlm, C.; Evander, M.; Bucht, G. Detection of Sindbis and Inkoo Virus RNA in Genetically Typed Mosquito Larvae Sampled in Northern Sweden. Vector-Borne Zoonotic Dis. 2016, 16, 461-467. [CrossRef] [PubMed]

8. Shaikevich, E.; Bogacheva, A.; Ganushkina, L. Dirofilaria and Wolbachia in Mosquitoes (Diptera: Culicidae) in Central European Russia and on the Black Sea Coast. Parasite 2019, 26. [CrossRef] [PubMed]

9. Melaun, C.; Zotzmann, S.; Santaella, V.G.; Werblow, A.; Zumkowski-Xylander, H.; Kraiczy, P.; Klimpel, S. Occurrence of Borrelia burgdorferi s.l. in Different Genera of Mosquitoes (Culicidae) in Central Europe. Ticks Tick-borne Dis. 2016, 7, 256-263. [CrossRef] 
10. Hernández-Triana, L.M.; Brugman, V.A.; Nikolova, N.I.; Ruiz-Arrondo, I.; Barrero, E.; Thorne, L.; de Marco, M.F.; Krüger, A.; Lumley, S.; Johnson, N.; et al. DNA Barcoding of British Mosquitoes (Diptera, Culicidae) to Support Species Identification, Discovery of Cryptic Genetic Diversity and Monitoring Invasive Species. ZooKeys 2019, 832, 57-76. [CrossRef] [PubMed]

11. Francy, D.B.; Jaenson, T.G.T.; Lundstrom, J.O.; Schildt, E.B.; Espmark, A.; Henriksson, B.; Niklasson, B. Ecologic Studies of Mosquitoes and Birds as Hosts of Ockelbo Virus in Sweden and Isolation of Inkoo and Batai Viruses from Mosquitoes. Am. J. Trop. Med. Hyg. 1989, 41, 355-363. [CrossRef]

12. Lundström, J.O.; Andersson, A.-C.C.; Bäckman, S.; Schäfer, M.L.; Forsman, M.; Thelaus, J. Transstadial Transmission of Francisella tularensis holarctica in Mosquitoes, Sweden. Emerg. Infect. Dis. 2011, 17, 794-799. [CrossRef] [PubMed]

13. Melbarde-Gorkusa, I.; Abolins, A.; Strumfa, I.; Martinsons, A.; Gardovskis, J. Human Dirofilariasis in Latvia-The First Case in Surgical Practice. Acta Chir. Latv. 2011, 11, 172-174. [CrossRef]

14. Lvov, S.D.; Pogorely Yu., A.; Skvortsova, T.M. Isolation of Tahyna Bunyavirus in the Arctic. Vopr. Virusol. 1985, 30, 736-740.

15. McLean, D.M.; Clarke, A.M.; Goddard, E.J.; Manes, A.S.; Montalbetti, C.A.; Pearson, R.E. California Encephalitis Virus Endemicity in the Yukon Territory, 1972. J. Hyg. 1973, 71, 391-402. [CrossRef]

16. Beebe, N.W. DNA Barcoding Mosquitoes: Advice for Potential Prospectors. Parasitol. 2018, 145, 622-633. [CrossRef]

17. Tabachnick, W.J. Nature, Nurture and Evolution of Intra-Species Variation in Mosquito Arbovirus Transmission Competence. Int. J. Environ. Res. Public Heal. 2013, 10, 249-277. [CrossRef]

18. Werren, J.H.; Zhang, W.; Guo, L.R. Evolution and Phylogeny of Wolbachia: Reproductive Parasites of Arthropods. Proc. R. Soc. B Biol. Sci. 1995, 261, 55-63.

19. Kageyama, D.; Narita, S.; Imamura, T.; Miyanoshita, A. Detection and Identification of Wolbachia Endosymbionts from Laboratory Stocks of Stored-Product Insect Pests and Their Parasitoids. J. Stored Prod. Res. 2010, 46, 13-19. [CrossRef]

20. Correa, C.C.; Ballard, J.W.O. Wolbachia Associations With Insects: Winning or Losing Against a Master Manipulator. Front. Ecol. Evol. 2016, 3, 506. [CrossRef]

21. Werren, J.H. Biology of Wolbachia. Annu. Rev. Entomol. 1997, 42, 587-609. [CrossRef]

22. Bordenstein, S.R.; O'Hara, F.P.; Werren, J.H. Wolbachia-Induced Incompatibility Precedes Other Hybrid Incompatibilities in Nasonia. Nature 2001, 409, 707-710. [CrossRef] [PubMed]

23. Ali, H.; Muhammad, A.; Bala, N.S.; Wang, G.; Chen, Z.; Peng, Z.; Hou, Y. Genomic Evaluations of Wolbachia and mtDNA in the Population of Coconut Hispine Beetle, Brontispa longissima (Coleoptera: Chrysomelidae). Mol. Phylogenet. Evol. 2018, 127, 1000-1009. [CrossRef] [PubMed]

24. Shaikevich, E.; Bogacheva, A.; Rakova, V.; Ganushkina, L.; Ilinsky, Y. Wolbachia Symbionts in Mosquitoes: Intra- and Intersupergroup Recombinations, Horizontal Transmission and Evolution. Mol. Phylogenet. Evol. 2019, 134, 24-34. [CrossRef]

25. Sicard, M.; Bonneau, M.; Weill, M. Wolbachia Prevalence, Diversity, and Ability to Induce Cytoplasmic Incompatibility in Mosquitoes. Curr. Opin. Insect Sci. 2019, 34, 12-20. [CrossRef] [PubMed]

26. Lilja, T.; Troell, K.; Kirik, H.; Lindström, A. A Distinct Group of North European Aedes vexans as Determined by Mitochondrial and Nuclear Markers. Med. Vet. Entomol. 2018, 32, 282-289. [CrossRef]

27. Sallum, M.A.M.; Schultz, T.R.; Foster, P.G.; Aronstein, K.; Wirtz, R.A.; Wilkerson, R.C. Phylogeny of Anophelinae (Diptera: Culicidae) Based on Nuclear Ribosomal and Mitochondrial DNA Sequences. Syst. Entomol. 2002, 27, 361-382. [CrossRef]

28. Krzywinski, J.; Wilkerson, R.C.; Besansky, N.J. Evolution of Mitochondrial and Ribosomal Gene Sequences in Anophelinae (Diptera: Culicidae): Implications for Phylogeny Reconstruction. Mol. Phylogenet. Evol. 2001, 18, 479-487. [CrossRef]

29. Kumar, N.P.; Rajavel, A.R.; Natarajan, R.; Jambulingam, P. DNA Barcodes Can Distinguish Species of Indian Mosquitoes (Diptera: Culicidae). J. Med. Entomol. 2007, 44, 01-07. [CrossRef]

30. Gunay, F.; Alten, B.; Simsek, F.; Aldemir, A.; Linton, Y.M. Barcoding Turkish Culex Mosquitoes to Facilitate Arbovirus Vector Incrimination Studies Reveals Hidden Diversity and New Potential Vectors. Acta Trop. 2015, 143, 112-120. [CrossRef] 
31. Simons, C.; Frati, F.; Beckenbach, A.; Crespi, B.; Liu, H.; Flook, P. Evolution, Weighting, and Phylogenetic Utility of Mitochondrial Gene Sequences and a Compilation of Conserved Polymerase Chain Reaction Primers. Ann. Entomol. Soc. Am. 1994, 87, 651-701. [CrossRef]

32. Ruiling, Z.; Tongkai, L.; Zhendong, H.; Guifen, Z.; Dezhen, M.; Zhong, Z. Genetic Analysis of Aedes albopictus (Diptera, Culicidae) Reveals a Deep Divergence in the Original Regions. Acta Trop. 2018, 185, 27-33. [CrossRef] [PubMed]

33. Makhawi, A.M.; Liu, X.-B.; Yang, S.-R.; Liu, Q.-Y. Genetic Variations of ND5 Gene of mtDNA in Populations of Anopheles sinensis (Diptera: Culicidae) Malaria Vector in China. Parasit. Vectors 2013, 6, 1-11. [CrossRef]

34. Yao, H.; Song, J.; Liu, C.; Luo, K.; Han, J.; Li, Y.; Pang, X.; Xu, H.; Zhu, Y.; Xiao, P.; et al. Use of ITS2 Region As the Universal DNA Barcode for Plants and Animals. PLoS ONE 2010, 5. [CrossRef]

35. Versteirt, V.; Boyer, S.; Damiens, D.; De Clercq, E.M.; Dekoninck, W.; Ducheyne, E.; Grootaert, P.; Garros, C.; Hance, T.; Hendrickx, G.; et al. Nationwide Inventory of Mosquito Biodiversity (Diptera: Culicidae) in Belgium, Europe. Bull. Entomol. Res. 2013, 103, 193-203. [CrossRef] [PubMed]

36. Folmer, O.; Black, M.; Hoeh, W.; Lutz, R.; Vrijenhoek, R. DNA Primers for Amplification of Mitochondrial Cytochrome C Oxidase Subunit I from Diverse Metazoan Invertebrates. Mol. Mar. Biol. Biotechnol. 1994, 3, 294-299. [PubMed]

37. Birungi, J.; Munstermann, L.E. Genetic Structure of Aedes albopictus (Diptera: Culicidae) Populations Based on Mitochondrial ND5 Sequences: Evidence for an Independent Invasion into Brazil and United States. Ann. Entomol. Soc. Am. 2002, 95, 125-132. [CrossRef]

38. Collins, F.H.; Paskewitz, S.M. A Review of the Use of Ribosomal DNA (rDNA) to Differentiate Among Cryptic Anopheles Species. Insect Mol. Biol. 1996, 5, 1-9. [CrossRef] [PubMed]

39. Braig, H.R.; Zhou, W.G.; Dobson, S.L.; O'Neill, S.L. Cloning and Characterization of a Gene Encoding the Major Surface Protein of the Bacterial Endosymbiont Wolbachia pipientis. J. Bacteriol. 1998, 180, 2373-2378. [CrossRef] [PubMed]

40. Hall, T.A. BioEdit: A user-friendly biological sequence alignment editor and analysis program for Windows 95/98/NT. Nucleic Acids Symp. Ser. 1999, 41, 95-98.

41. Kumar, S.; Stecher, G.; Li, M.; Knyaz, C.; Tamura, K. MEGA X: Molecular Evolutionary Genetics Analysis across Computing Platforms. Mol. Biol. Evol. 2018, 35, 1547-1549. [CrossRef]

42. Tamura, K. Estimation of the Number of Nucleotide Substitutions When There Are Strong Transition-Transversion and G+C-Content Biases. Mol. Biol. Evol. 1992, 9, 678-687. [PubMed]

43. Kimura, M. A Simple Method for Estimating Evolutionary Rates of Base Substitutions Through Comparative Studies of Nucleotide Sequences. J. Mol. Evol. 1980, 16, 111-120. [CrossRef] [PubMed]

44. Nei, M.; Kumar, S. Molecular Evolution and Phylogenetics; Oxford University Press, Incorporated: Cary, NC, USA, 2000.

45. Turelli, M.; Hoffmann, A.A. Cytoplasmic Incompatibility in Drosophila simulans: Dynamics and Parameter Estimates from Natural Populations. Genetics 1995, 140, 1319-1338. [PubMed]

46. Raukas, A. When and How Did the Continental Ice Retreat from Estonia? Quat. Int. 2009, $207,50-57$. [CrossRef]

47. Patton, H.; Hubbard, A.; Andreassen, K.; Auriac, A.; Whitehouse, P.L.; Stroeven, A.P.; Shackleton, C.; Winsborrow, M.; Heyman, J.; Hall, A.M. Deglaciation of the Eurasian Ice Sheet Complex. Quat. Sci. Rev. 2017, 169, 148-172. [CrossRef]

48. Hewitt, G.M. Post-Glacial Re-Colonization of European Biota. Biol. J. Linn. Soc. 1999, 68, 87-112. [CrossRef]

49. Song, H.; Buhay, J.E.; Whiting, M.F.; Crandall, K.A. Many Species in One: DNA Barcoding Overestimates the Number of Species When Nuclear Mitochondrial Pseudogenes are Coamplified. Proc. Natl. Acad. Sci. USA 2008, 105, 13486-13491. [CrossRef]

50. Song, H.; Moulton, M.J.; Whiting, M.F. Rampant Nuclear Insertion of mtDNA across Diverse Lineages with in Orthoptera (Insecta). PLoS ONE 2014, 9, e110508. [CrossRef]

51. Ding, Y.R.; Li, B.; Zhang, Y.J.; Mao, Q.M.; Chen, B. Complete Mitogenome of Anopheles sinensis and Mitochondrial Insertion Segments in the Nuclear Genomes of 19 Mosquito Species. PLoS ONE 2018, 13, e0204667. [CrossRef] 
52. Behura, S.K.; Lobo, N.F.; Haas, B.; DeBruyn, B.; Lovin, D.D.; Shumway, M.F.; Puiu, D.; Romero-Severson, J.; Nene, V.; Severson, D.W. Complete Sequences of Mitochondria Genomes of Aedes aegypti and Culex quinquefasciatus and Comparative Analysis of Mitochondrial DNA Fragments Inserted in the Nuclear Genomes. Insect Biochem. Mol. Biol. 2011, 41, 770-777. [CrossRef]

53. Perna, N.T.; Kocher, T.D. Mitochondrial DNA: Molecular Fossils in the Nucleus. Curr. Biol. 1996, 6, $128-129$. [CrossRef]

54. Lopez, J.V.; Culver, M.; Stephens, J.C.; Johnson, W.E.; O’Brien, S.J. Rates of Nuclear and Cytoplasmic Mitochondrial DNA Sequence Divergence in Mammals. Mol. Biol. Evol. 1997, 14, 277-286. [CrossRef] [PubMed]

55. Frey, J.E.; Frey, B. Origin of Intra-Individual Variation in PCR-Amplified Mitochondrial Cytochrome Oxidase I of Thrips tabaci (Thysanoptera: Thripidae): Mitochondrial Heteroplasmy or Nuclear Integration? Hereditas 2004, 140, 92-98. [CrossRef] [PubMed]

(C) 2020 by the authors. Licensee MDPI, Basel, Switzerland. This article is an open access article distributed under the terms and conditions of the Creative Commons Attribution (CC BY) license (http://creativecommons.org/licenses/by/4.0/). 